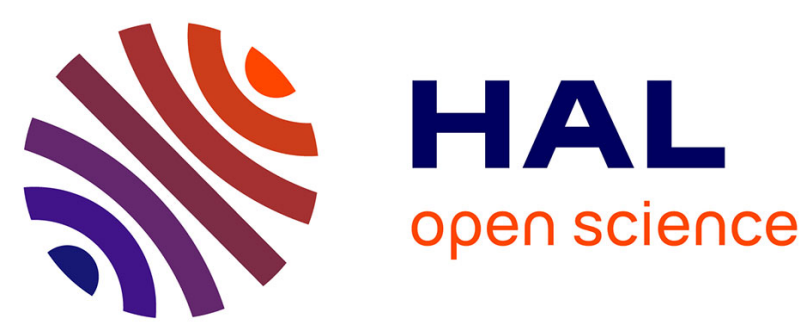

\title{
Three-Dimensional Unsteady MHD Modeling of a Low-Current High-Voltage Nontransferred DC Plasma Torch Operating With Air
}

Alexandre Lebouvier, Clarisse Delalondre, François Fresnet, Valérie Boch, Vandad-Julien Rohani, François Cauneau, Laurent Fulcheri

\section{To cite this version:}

Alexandre Lebouvier, Clarisse Delalondre, François Fresnet, Valérie Boch, Vandad-Julien Rohani, et al.. Three-Dimensional Unsteady MHD Modeling of a Low-Current High-Voltage Nontransferred DC Plasma Torch Operating With Air. IEEE Transactions on Plasma Science, 2011, 39 (9), pp.1889-1899. 10.1109/TPS.2011.2160208 . hal-00623649

\section{HAL Id: hal-00623649}

https://hal-mines-paristech.archives-ouvertes.fr/hal-00623649

Submitted on 14 Sep 2011

HAL is a multi-disciplinary open access archive for the deposit and dissemination of scientific research documents, whether they are published or not. The documents may come from teaching and research institutions in France or abroad, or from public or private research centers.
L'archive ouverte pluridisciplinaire HAL, est destinée au dépôt et à la diffusion de documents scientifiques de niveau recherche, publiés ou non, émanant des établissements d'enseignement et de recherche français ou étrangers, des laboratoires publics ou privés. 


\title{
Three-Dimensional Unsteady MHD Modeling of a Low Current - High Voltage Non-Transferred DC Plasma Torch Operating With Air
}

\author{
Alexandre Lebouvier, Clarisse Delalondre, Francois Fresnet, Valerie Boch, Vandad Rohani, Francois Cauneau \\ and Laurent Fulcheri
}

\begin{abstract}
We present in this paper the MHD modeling of a DC plasma torch operating with air under very peculiar high voltage-low current conditions. The model developed is $3 \mathrm{D}$, timedependent and assumes LTE. The study has been carried out considering an axial injection of air with flow rates varying in the range $0.16-0.5 \mathrm{~g} / \mathrm{s}$ and currents varying in the range 300 $600 \mathrm{~mA}$.

The numerical modeling has been developed using Code_Saturne, CFD software developed by EDF R\&D which is based on co-located finite volume.

After a detailed description of the model, results are presented, analyzed and discussed. The influence of current and air flow rate over the arc characteristics are studied in terms of temperature, velocity, electrical potential, Joule heating and arc root motion. Regarding numerical issues, the MHD modeling of low current - high voltage arc discharge is particularly tricky since, below $1 \mathrm{~A}$, the self-induced magnetic field becomes negligible and the convection effects induce a highly irregular and unstable motion of the arc column. However, despite these difficulties, the numerical model has been successfully implemented. Numerical results have shown good correlation and good trends with experimental ones despite a discrepancy probably due to the LTE assumption. The model gave fruitful and significant information on parameters that could hardly be obtained experimentally. This preliminary work is likely to open the way towards a better understanding of low current arc discharges, which technologies are currently encountering an important development in many application fields.
\end{abstract}

Index Terms-3D MHD unsteady modeling, Low current DC arc discharge, non-transferred plasma torch.

\section{INTRODUCTION}

$\mathbf{F}$ OR many years, numerical modeling became a unique and powerful tool for the development and the optimization of plasma processes. With computing power improvement, models get more and more sophisticated and close to real conditions thus allowing today the simulation of three-dimensional and unsteady systems with detailed geometry description. Numerous fluid models have been reported in the literature mostly on direct current (DC) arc discharge modeling using

Manuscript received February 2, 2011. This work was supported by Renault SAS, Guyancourt, France.

A. Lebouvier, V. Rohani, F. Cauneau and L. Fulcheri are with MINES ParisTech, Center for Energy and Processes, Rue Claude Daunesse, BP 207, 06904 Sophia Antipolis, France (email: laurent.fulcheri@mines-paristech.fr).

C. Delalondre is with EDF R\&D, MFEE Department, 6 quai Watier, 78400 Chatou, France.

F. Fresnet and V. Boch are with Technocentre Renault, DREAM/DTAA Service 68240, 78288 Guyancourt, France.

Digital Object Identifier high current above $100 \mathrm{~A}$ [1], [2] including: free burning arcs [3], [4], transferred arcs [5]-[7] and non-transferred arcs [8]-[11]. Many DC arc plasma torches models have been developed for different applications [12] as: cutting [13], welding [14], deposition and spraying [8]-[11], [15], [16], steelmaking [7], waste disposal [17] and ultra fine particle production [18]. These thermal plasmas generally work under low-medium voltage between 30 and $500 \mathrm{~V}$ [2]. In nontransferred plasma torch, the arc behavior can generally be classified into three operation modes : steady, takeover and restrike modes respectively [2]. The steady mode corresponds to a fixed position of the arc attachment whereas the takeover mode corresponds to a quasi-periodic fluctuation of the voltage drop and hence of the arc movement. The restrike mode is characterized by a highly unstable movement of the arc where the reattachment phenomenon plays a significant role. The first models were two-dimensional (2D) or 2D axisymmetric thus, the vortex inflow and the arc root attachment could not be perfectly reproduced [7], [19], [20]. With the improvement of computing power, many research teams moved towards threedimensional models which are closer to real configurations [4]. Most of these models assume the local thermodynamic equilibrium (LTE) except $e$.g. Trelles et al. [21] and Park et al. [22] who developed non-LTE (NLTE) models in argon. The calculations are often realized in a simple gas, mainly argon [4], [15], [18], [20] but also nitrogen [5], pure oxygen [13], or a gas mixture: air [17], $\mathrm{Ar} / \mathrm{H}_{2}$ [8], $\mathrm{Ar} / \mathrm{N}_{2}$ [9]-[11]. The main focuses of arc plasma torch modeling are the arc root displacement and attachment [16], [17], and the metal electrode evaporation [14], [16]. Although the laminar flow regime is commonly used for modeling plasma torch [6], [8], [10], [17], [23], literature reports few studies using turbulent k- $\epsilon$ model [15], [18], Rij- $\epsilon$ and low-Re models [24], comparing laminar to standard $\mathrm{k}-\epsilon$ model [25], or comparing several turbulent models (standard k- $\epsilon$, RNG k- $\epsilon$, realizable k- $\epsilon$ ) [13].

For several years, researches carried out at CEP (Center for Energy and Processes, MINES ParisTech) in the field of hydrocarbons reforming led to the development of a very peculiar DC plasma torch technology operating under low current - high voltage conditions: typically in the range $400 \mathrm{~mA}$ and $2 \mathrm{kV}$ respectively. This type of torch is a non-thermal atmospheric plasma torch and, in some operating points, can be assimilated to a LCGA (Low Current Gliding Arc) as we work under $1 \mathrm{~A}$ [26]. The high degree of non-equilibrium of this torch is promising for chemical applications to support 
chemical reactions selectively [26], but suffer from a lack of knowledge of its physics and chemistry. Our researches led to the development of basic knowledge on both experimental [27], [28] and numerical [29], [30] sides. Unfortunately, whereas many studies have been dedicated to high current plasma discharges, the literature on MHD modeling of low current - high voltage plasma torches is very poor and the domain remains almost unexplored. One of the main reason explaining the lack of studies dedicated to this purpose is probably due to the fact that, at low current, the self-induced magnetic field becomes negligible and the convection effects induce a highly irregular motion of the arc column. These arc motion instabilities imply very unstable physical phenomena. Thus, one of the most challenging issue in the field of plasma modeling for the next coming years is to be able to simulate very low-current arc discharges owing to important numerical instabilities deriving from physical instabilities.

Different numerical models developed for plasma reforming addressing thermodynamics and kinetics issues have been reviewed in Ref. [31]. On the other hand, Bromberg et al. [32] and Fridman et al. [33] used computational fluid dynamics (CFD) codes to simulate the hydrodynamic flows in the torch with considering neither kinetic reactions nor MHD equations. In the first paper, the plasma is not considered and the study has been focused on the methane/air mixing at the location of the plasma. In the second one, the plasma is considered as a source term of power and the reverse vortex flow influence on the plasma is investigated.

In the first part of this paper, the model assumptions, boundary conditions, equations and simulation parameters are successively presented. In the second part of this paper, the low current arc discharge behavior is presented, analyzed and discussed in terms of temperature, velocity, electrical potential, Joule heating and arc root velocity with a special attention being paid to evaluate the influence of arc current and air flow rate.

\section{MATHEMATICAL MODEL}

\section{A. Assumptions}

The three-dimensional model studied is based on the following main assumptions:

- The plasma is considered as a single continuous fluid (Air).

- The plasma is optically thin and at Local Thermodynamic Equilibrium (LTE).

- The gas is treated as semi-compressible because the Mach number is lower than 0.2 .

- The gas flow is laminar and time-dependent.

- Gravitational effects are taken into account (-x direction).

Let us point out that whereas high current arcs or high power-density plasmas [34] are commonly assumed to be in LTE. For low current or low power density arcs, which has a high degree of non-equilibrium, this hypothesis is generally not correct. It has been demonstrated that this assumption can imply great differences in the arc behavior and characteristics [21]. However, even if this is a strong assumption, the LTE assumption has been considered due to highly challenging numerical issues linked with the low current. The objective of this study was to get preliminary information on transport phenomena including mass, momentum, and energy as well as on the gas flow and temperature fields. Obviously, it would be interesting subsequently, in a later phase, to develop more sophisticated NLTE models such as two-temperature models.

\section{B. Governing equations}

The model can be defined by the set of following equations based on fluid dynamics Navier-Stokes and Maxwell electromagnetic equations respectively. All the equations are written in a Cartesian system (Ox, Oy, Oz). In thermal plasmas, which are assumed to be electronically neutral, the only resulting force applied on a volume element is the Lorentz Force $\left(\mathrm{N} / \mathrm{m}^{3}\right)$ :

$$
\vec{F}_{L}=\boldsymbol{J} \times \boldsymbol{B}
$$

where $J$ and $B$ correspond to the electric current density vector $\left(\mathrm{A} / \mathrm{m}^{2}\right)$ and the magnetic field $(\mathrm{T})$ respectively. The generalized Ohm's law approximation commonly used in electric arc modeling [2] is :

$$
\boldsymbol{J}=\sigma \boldsymbol{E}
$$

where $\sigma$ and $E$ represent the electric conductivity $(\mathrm{S} / \mathrm{m})$ and the electric field $(\mathrm{V} / \mathrm{m})$ respectively. Neglecting the Neumann's electromotive field, the electrical field can be linked to the electrical potential $\phi(\mathrm{V})$ by the following relation:

$$
\boldsymbol{E}=-\nabla \phi
$$

In absence of external magnetic field, the electric potential equation is approximated to:

$$
-\nabla \cdot(\sigma \nabla \phi)=0
$$

The magnetic field and the magnetic vector potential (T.m) are related by the following relation:

$$
\boldsymbol{B}=\nabla \times \boldsymbol{A}
$$

The Maxwell-Ampere equation is:

$$
\Delta \boldsymbol{A}=-\mu_{0} \boldsymbol{J}
$$

where $\mu_{0}$ is the vacuum permeability.

The set of Navier-Stokes fluid conservation equations is presented below.

Mass conservation

$$
\frac{\partial \rho}{\partial t}+\nabla \cdot(\rho \boldsymbol{V})=0
$$

where $\rho$ and $V$ are the mass density and the velocity vector.

Energy conservation equation

$$
\frac{\partial \rho h}{\partial t}+\nabla \cdot \rho h \boldsymbol{V}-\nabla \cdot \frac{\lambda}{C_{p}} \nabla h=\boldsymbol{J} \cdot \boldsymbol{E}-S_{\text {rad }}
$$

where $\mathrm{h}, \lambda, \mathrm{C}_{p}$ and $\mathrm{S}_{\text {rad }}$ are the gas enthalpy, the thermal conductivity, the specific heat and the radiation losses respectively. 


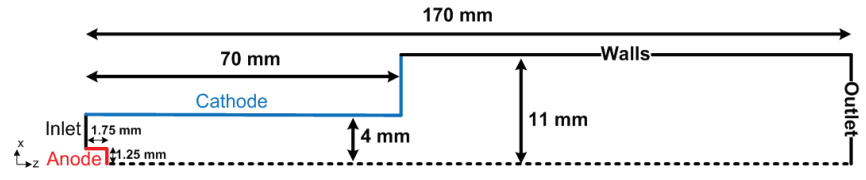

Fig. 1. Schematic of the plasma torch.

\section{Momentum equation}

$$
\frac{\partial \rho \boldsymbol{V}}{\partial t}+\nabla \cdot(\rho \boldsymbol{V} \otimes \boldsymbol{V})=-\nabla p+\nabla \cdot \overline{\bar{\tau}}+\boldsymbol{J} \times \boldsymbol{B}+\rho \boldsymbol{g}
$$

where $\mathrm{p}, \tau$ and $g$ are the pressure, the shear stress tensor and the gravity vector respectively.

The study was carried out for an arc discharge operating with air. The properties data have been taken from [35] for enthalpy, density, specific heat, electrical conductivity, dynamic viscosity and thermal conductivity. For the source radiation, the net emission coefficients have been taken from [36].

The resistive MHD equations have been solved using Code_Saturne v. 1.3, developed by EDF R\&D. The Code_Saturne electric arc module has been used. This CFD software is based on co-located finite volume [37]. Code_Saturne's capabilities enable the handling of incompressible and expandable flows with heat transfer using SOLU convective scheme (Second Order Linear Upwind) and SIMPLEC pressure correction scheme (Semi-Implicit Method for Pressure-Linked Equations, Consistent) [38].

\section{Computational grid and boundary conditions}

The torch geometry corresponding to the real experimental set-up, is presented on Fig. 1. It is composed of two separated zones: the plasma zone and the post-discharge zone with $70 \mathrm{~mm} / 4 \mathrm{~mm}$ and $100 \mathrm{~mm} / 11 \mathrm{~mm}$ length / inner radius respectively. Let us point out that, under real reactive operating conditions, the plasma zone is the part where the arc plasma really takes place whereas the post-discharge zone is an active or passive zone, located downstream the plasma zone where, reactions ignited in the plasma zone continue to take place.

Usually, in DC plasma torches, the tip electrode is the cathode. In our case, the system operates under inversed polarity. The tip electrode, on which a positive electrical potential is applied, being the anode whereas the cylinder electrode is grounded and acts as the cathode. Indeed, previous works have demonstrated this configuration was the most suitable for low current systems [30].

The grid mesh, shown on Fig. 2, is exclusively composed of hexa-elements and contained 339000 cells. Cubic cells of $\Delta \mathrm{x}=0.044 \mathrm{~mm}$ compose the center of the computational grid. The mean axial and radial spacing grid are $0.7 \mathrm{~mm}$ and $0.21 \mathrm{~mm}$ respectively. These values are very similar to the ones used by Freton et al. [17]. This very fine grid was chosen to compute correctly the gradients of all transport variables into the arc column. The grid is axially finer near the anodic and the cathodic arc root attachment position.

The boundary conditions are detailed in Table I. The atmospheric pressure is imposed at the outlet. The temperature of

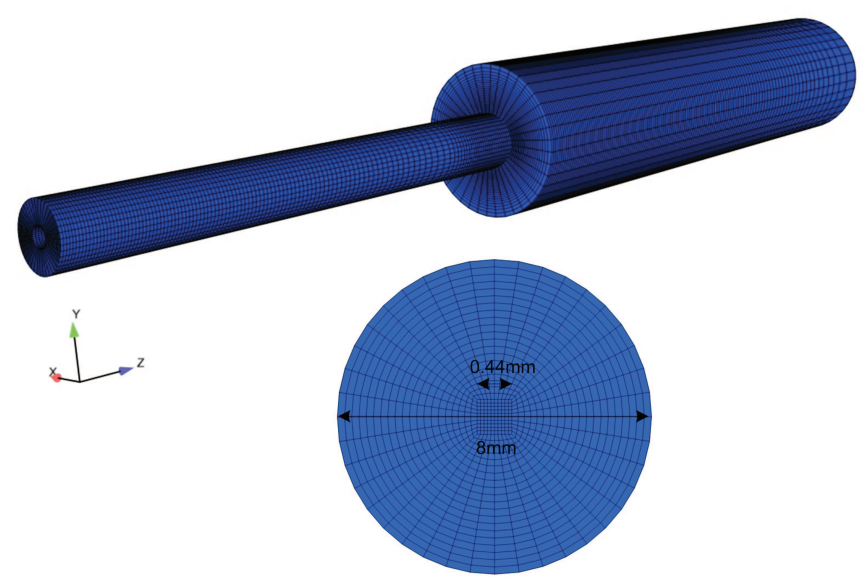

Fig. 2. Computational grid of the plasma torch.

the injected air is $600 \mathrm{~K}$. The walls are considered adiabatic. At the first time step, an atmospheric pressure and a temperature of $600 \mathrm{~K}$ is applied to the whole domain.

The potentiel to the cathode is imposed to $0 \mathrm{~V}$, and the potential to the anode is calculated from the previous time step. The voltage drop in the sheath is not included in the model. The potential results correspond to the voltage drop in the arc column. In our case, the electrical current is very low, so it is difficult to assume a value of electrical voltage drop in the cathodic and anodic sheaths. For high intensity electric arcs, authors generally used an imposed value of 3 to $10 \mathrm{~V}$ for the potential drop in the sheaths [4], [8], [39].

A null-flux condition is applied for the heat conduction at the electrodes. Even if this assumption is strong, it can be justified by the fact that the electrodes are not water-cooled so the losses at the electrodes are not as significant as they are in thermal torches.Nevertheless, in a next step model, we will take into account the electrode sheath by introducing a global model based on the energy exchange in the cathodic and anodic sheath [8], [40].

\section{Simulation parameters}

The time step $\Delta \mathrm{t}$ is set to $10 \mu \mathrm{s}$ as Chemartin et al. [3], [41]. This time step allows obtaining fair plasma characteristics with a reasonable computation time. Freton et al. [17] and Park et al. [42] have used a $5 \mu$ s time step after a parametric study.

At the first time step, a hot temperature channel is artificially created to ignite the arc such as proposed, for example, by Moreau et al. [8]. The channel has a $0.8 \mathrm{~mm}$ radius. The temperature imposed in the initial channel is $6000 \mathrm{~K}$ for starting calculation (cf. Fig. 3). The initial anode voltage drop is set to $1000 \mathrm{~V}$. For the first 50 time steps i.e. $500 \mu \mathrm{s}$, the inflow is $1 \%$ of the total inflow in order to allow the correct arc ignition. Subsequently, for the 150 following time steps, a linear velocity ramp is applied at the inlet to increase the inflow from 1 to $100 \%$.

The current target is set between $300 \mathrm{~mA}$ and $600 \mathrm{~mA}$. The current is mesured by the integral of the current density in a Z-normal plane $\mathrm{S}_{z}$ (cf. Eq. 10), located $1.5 \mathrm{~mm}$ after the 
TABLE I

BOUNDARY CONDITIONS OF THE 3D MHD MODEL.

\begin{tabular}{cccccc}
\hline & Inlet & Outlet & Walls & Anode & Cathode \\
\hline$u(\mathrm{~m} / \mathrm{s})$ & 0 & $\frac{\partial u}{\partial \boldsymbol{n}}=0$ & 0 & 0 & 0 \\
$v(\mathrm{~m} / \mathrm{s})$ & 0 & $\frac{\partial v}{\partial \boldsymbol{n}}=0$ & 0 & 0 & 0 \\
$w(\mathrm{~m} / \mathrm{s})$ & 6.1 to 19.1 & $\frac{\partial w}{\partial \boldsymbol{n}}=0$ & 0 & 0 & 0 \\
$T(\mathrm{~K})$ & 600 & $\frac{\partial T}{\partial \boldsymbol{n}}=0$ & $\frac{\partial T}{\partial \boldsymbol{n}}=0$ & $\frac{\partial T}{\partial \boldsymbol{n}}=0$ & $\frac{\partial T}{\partial \boldsymbol{n}}=0$ \\
$\phi(\mathrm{V})$ & $\frac{\partial \phi}{\partial \boldsymbol{n}}=0$ & $\frac{\partial \phi}{\partial \boldsymbol{n}}=0$ & $\frac{\partial \phi}{\partial \boldsymbol{n}}=0$ & $\phi(n)$ & 0 \\
$P(\mathrm{~Pa})$ & $\frac{\partial P}{\partial \boldsymbol{n}}=0$ & $1.01310^{5}$ & $\frac{\partial P}{\partial \boldsymbol{n}}=0$ & $\frac{\partial P}{\partial \boldsymbol{n}}=0$ & $\frac{\partial P}{\partial \boldsymbol{n}}=0$ \\
$A_{x}(\mathrm{~T} . \mathrm{m})$ & $\frac{\partial A_{x}}{\partial \boldsymbol{n}}=0$ & 0 & $\frac{\partial A_{x}}{\partial \boldsymbol{n}}=0$ & $\frac{\partial A_{x}}{\partial \boldsymbol{n}}=0$ & $\frac{\partial A_{x}}{\partial \boldsymbol{n}}=0$ \\
$A_{y}(\mathrm{~T} . \mathrm{m})$ & $\frac{\partial A_{y}}{\partial \boldsymbol{n}}=0$ & 0 & $\frac{\partial A_{y}}{\partial \boldsymbol{n}}=0$ & $\frac{\partial A_{y}}{\partial \boldsymbol{n}}=0$ & $\frac{\partial A_{y}}{\partial \boldsymbol{n}}=0$ \\
$A_{z}(\mathrm{~T} . \mathrm{m})$ & $\frac{\partial A_{z}}{\partial \boldsymbol{n}}=0$ & 0 & $\frac{\partial A_{z}}{\partial \boldsymbol{n}}=0$ & $\frac{\partial A_{z}}{\partial \boldsymbol{n}}=0$ & $\frac{\partial A_{z}}{\partial \boldsymbol{n}}=0$ \\
\hline
\end{tabular}

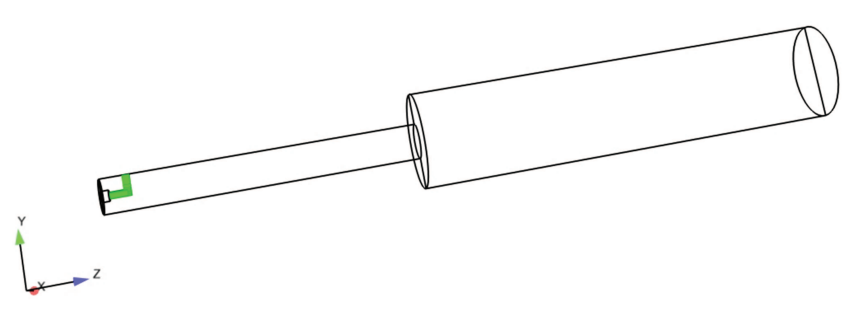

Fig. 3. View of the initial hot temperature channel at the first time step.

anode. At each time step, the anodic electrical potential $\phi^{n}$ is fitted to maintain the current target from Eq. 11.

$$
\begin{gathered}
I=\iint_{S_{z}} \boldsymbol{J} \cdot d \boldsymbol{S} \\
\phi^{n}=\frac{I_{\text {target }}}{I_{\text {mesured }}} \phi^{n-1}
\end{gathered}
$$

2000 time steps have been considered, corresponding to a numerical time of $20 \mathrm{~ms}$. The calculations have been realized on 8 processors (Intel Xeon $2.66 \mathrm{GHz}$ ) for 30 hours. That corresponds to a calculation time of around $55 \mathrm{~s}$ for each time step. The number of under iteration is around 2300 for pressure, 1300 for potential vector, and under 100 for enthalpy and velocity.

\section{RESULTS}

A. Results for $I=400 \mathrm{~mA}$ and $Q_{\text {air }}=0.32 \mathrm{~g} / \mathrm{s}$

In this section, we present results for an electrical current of $400 \mathrm{~mA}$ and an air flow rate of $0.32 \mathrm{~g} / \mathrm{s}$.

Fig. 4 represents the evolution of the temperature. We can observe that the arc root moves along the same plane as the ignition plane $(\mathrm{Oy}, \mathrm{Oz})$ due to the axial injection. Once the arc root has reached the cathode tip, it remains attached to the cathode tip at approximately $1.30 \mathrm{~mm}$ above the exit. The arc root path follows the cathode shape at the exit. Indeed, in this zone, the velocity magnitude is close to zero (cf. Fig 5) because of the dead zone created by the sudden section enlargement. In this zone, the cathodic arc root is less disturbed by the gas inflow and the dead zone constitutes a favourable arc root attachment point.

The magnetic field is produced by the local curvature of the current path and the self-induced magnetic field. The arc dynamics inside the torch is the result of the imbalance between the electromagnetic forces and the flow drag. As expected, the magnetic field magnitude is very low. Its maximum value reaches $0.7 \mathrm{mT}$ at the cathode tip where tip effect is the highest. As a result, the Lorentz forces are also very low (up to $120 \mathrm{~N} / \mathrm{m}^{3}$ ). Around the arc core, the mean value of the magnetic field magnitude is around $0.1 \mathrm{mT}$. These very low values explain mainly the instabilities observed in low current plasma torches compared to high current plasma torches, much more stable. The magnetic field is so low that the arc column is only stabilized by the hydrodynamic effects, especially by the wall or vortex stabilization commonly used in low current 


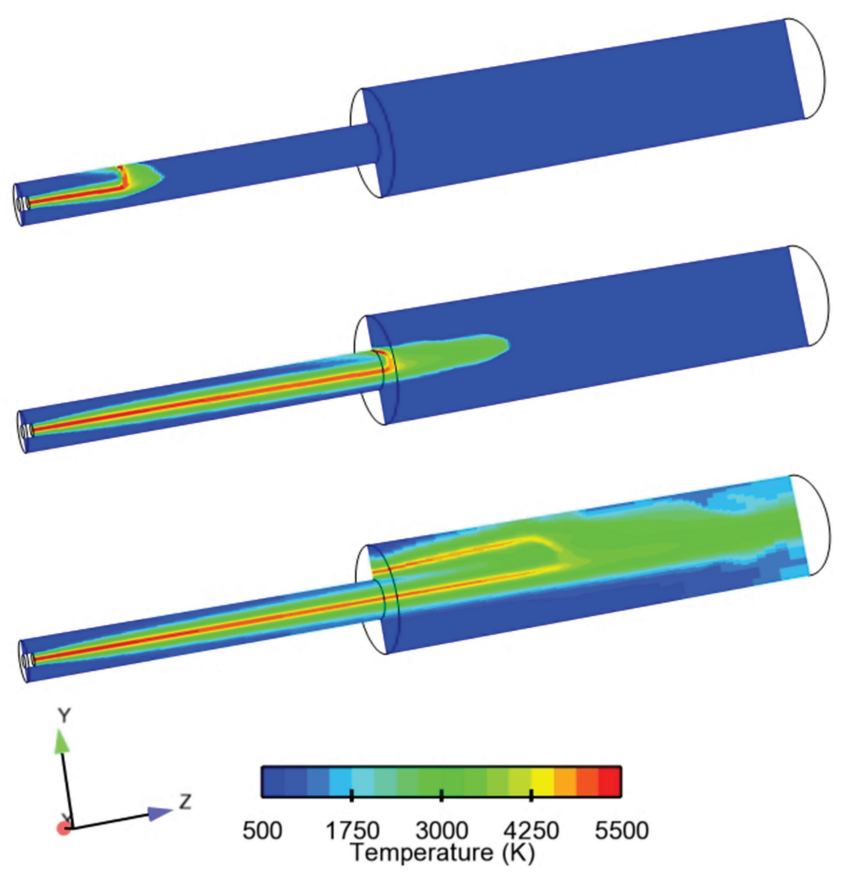

Fig. 4. Representation of the temperature field displaying the evolution of the arc shape in a cross-section for three specific times $(\mathrm{t}=2,5$ and $20 \mathrm{~ms})$. $\mathrm{I}=400 \mathrm{~mA}$. Q $\mathrm{air}=0.32 \mathrm{~g} / \mathrm{s}$.

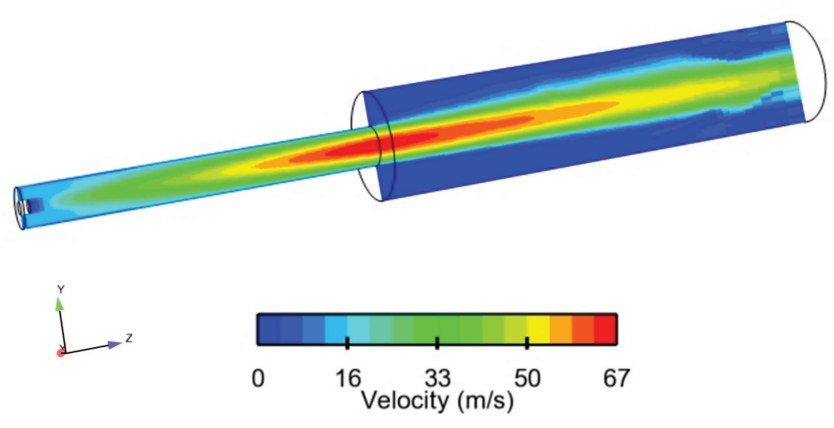

Fig. 5. Representation of the velocity magnitude distribution. $\mathrm{I}=400 \mathrm{~mA}$. $\mathrm{Q}_{\text {air }}=0.32 \mathrm{~g} / \mathrm{s}$.

- high voltage torch.

The maximum velocity is $67 \mathrm{~m} / \mathrm{s}$ and is located at the cathode tip. The velocity magnitude distribution is not symmetric due to the arc curve. Once the inlet velocity has reached its maximum, the arc root velocity can be estimated to $15.2 \mathrm{~m} / \mathrm{s}$ along the cathode inner surface. This calculated velocity is higher than the average velocity in the nozzle $(w=11 \mathrm{~m} / \mathrm{s})$ because of the thermal effects. On the other hand, the Lorentz force is so low that the induced convection effect can be neglected.

The anodic and cathodic arc root temperature values are around 5500 and $5100 \mathrm{~K}$ respectively. This temperature corresponds to the temperature of the plasma at the interface between the electrode sheath region and the arc column. The arc column is very stable inside the cathode essentially due to the axial injection and the laminar flow assumption. One can observe on Fig. 6 that the arc core temperature in the cathode reaches $5300 \mathrm{~K}$ with a significant temperature gradient

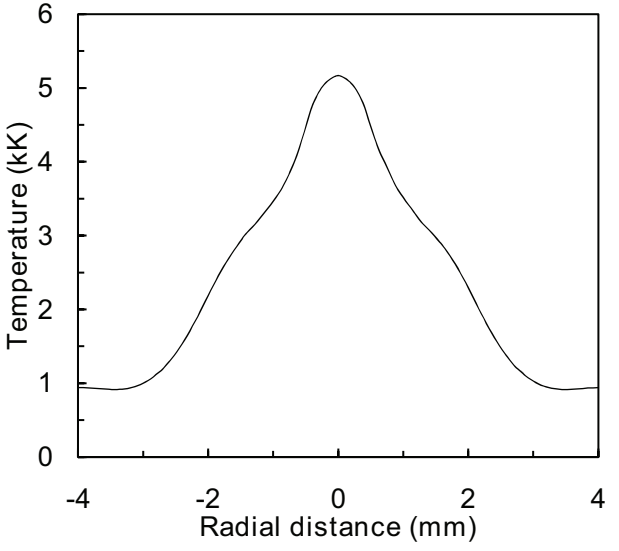

Fig. 6. Numerical temperature profile in the radial direction taken in the middle of the cathode. I $=400 \mathrm{~mA}$. Q Qir $=0.32 \mathrm{~g} / \mathrm{s}$.
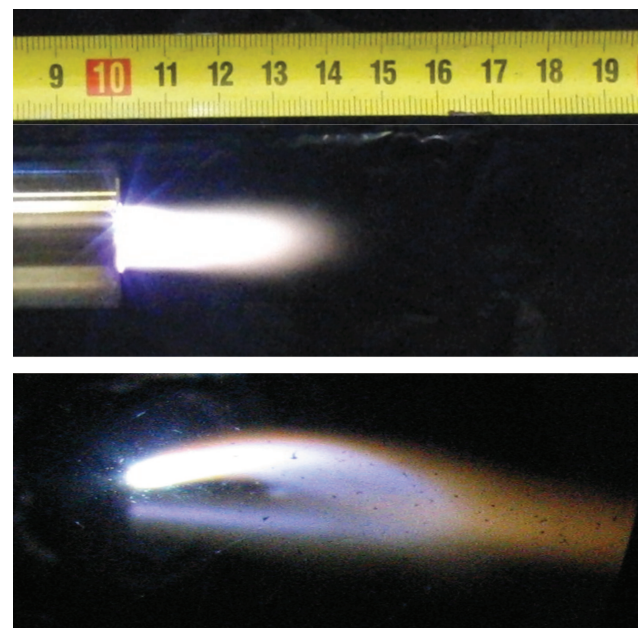

Fig. 7. Photographs of the experimental plasma torch tip for $\mathrm{Q}_{\text {air }}=0.32$ $\mathrm{g} / \mathrm{s}$. I $=400 \mathrm{~mA}$. Vortex injection.

between the center of cathode and its borders $(\sim 1500 \mathrm{~K} / \mathrm{mm})$.

Fig. 7 presents a real photographs of the plasma from experiments in close conditions. This picture confirms the phenomenon predicted by the simulation, previously presented on Fig. 4. The plasma plume observed by the experiment has the same shape as that numerically obtained. The cathodic arc root becomes attached to a point located above the exit.

We can also observe on Fig. 7 that the arc root radiations are higher than the arc core radiations. This difference is not observed by the simulation (cf. Fig. 8), the arc root is as bright as the arc core. This phenomenon can probably be explained by the fact that the model does not take into account the electrode metal evaporation. Indeed, the cathode being composed of stainless steel, it is composed by more than $60 \%$ of iron and it is well known that iron net emission is very high [43]. We can also see on this picture that the plasma plume length, which is about $55 \mathrm{~mm}$ numerically, is close to the experimental one, which is around $45 \mathrm{~mm}$.

As assumed by Selvan and coworkers [11], the arc core radius is the radial distance along the anode from the centerline to the point where the current density is zero. In practice, the zero current density is supposed being achieved when 


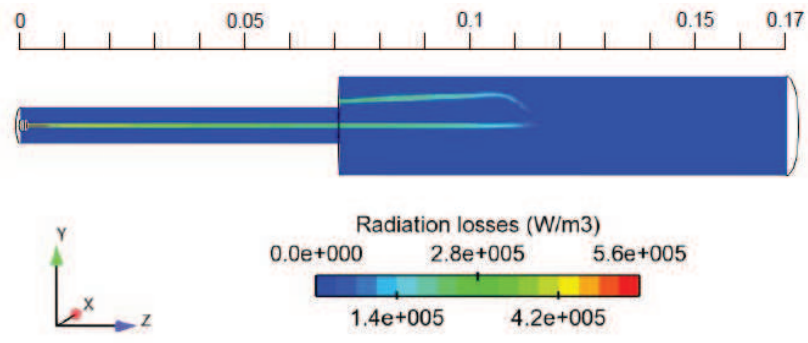

Fig. 8. Representation of the radiation emission distribution. $I=400 \mathrm{~mA}$. $\mathrm{Q}_{\text {air }}=0.32 \mathrm{~g} / \mathrm{s}$.

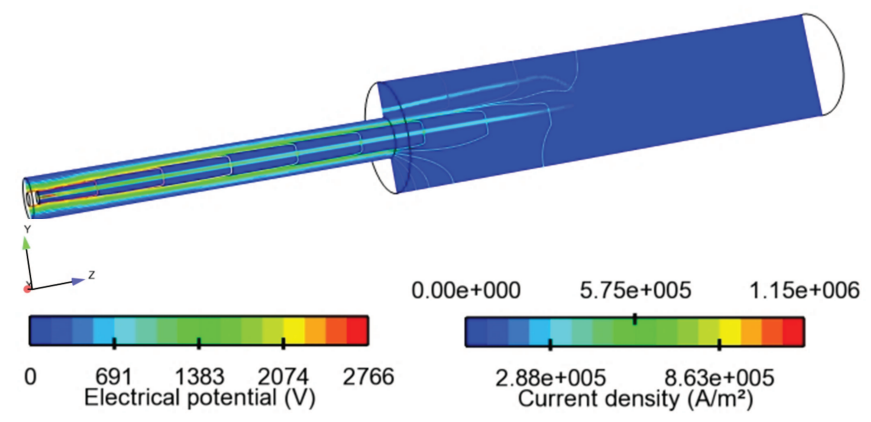

Fig. 9. View of the current density and isopotentials. I $=400 \mathrm{~mA}$. Qair $=$ $0.32 \mathrm{~g} / \mathrm{s}$.

the current density is 2 orders of magnitude smaller than the maximum current density which is $115 \mathrm{~A} / \mathrm{cm}^{2}$. The current density is shown on Fig. 9. By this technique, the arc core radius can be estimated to $0.5 \mathrm{~mm}$. This information is hardly accessible by the experiment.

On the other hand, the radius of the most emitting zone, has been experimentally estimated, to the naked eye, to $1 \mathrm{~mm}$ at the torch exit. It can be compared to the radius value of the most emitting zone found by the simulation. From Fig. 8, this value is around $0.83 \mathrm{~mm}$, so demonstrating the good correlation between the numerical and the experimental results.

The voltage drop and the inlet velocity ramp are presented on Fig. 10. After $500 \mu$ s, the arc is blown by the air flow rate. The higher the arc length, the higher the voltage. Indeed, it is well known that the arc voltage varies quasi-linearly with the arc length. We can observe few low instabilities ( $f=20$ $\mathrm{kHz}$ ) in the range $1.3-6 \mathrm{~ms}$. These instabilities are probably numerical instabilities due to the sudden high stretch of the low current arc.

Once the arc root has reached the cathode tip, the mean voltage is equal to $2.7 \mathrm{kV}$ and corresponds to a deposited plasma power of $1.1 \mathrm{~kW}$. For that case, a typical experimental oscillogram is displayed on Fig. 11 and gives a mean voltage $30 \%(1.9 \mathrm{kV})$ lower than the simulated one. As demonstrated by Trelles et al. [21], the total voltage drop for a NLTE model of a high current plasma torch can be $50 \%$ lower than for a LTE model. Indeed, for NLTE models, the electron temperature and the electrical conductivity are higher than in LTE models. Hence the resistance to the current flow decreases and leads to a decrease of the voltage drop decrease.

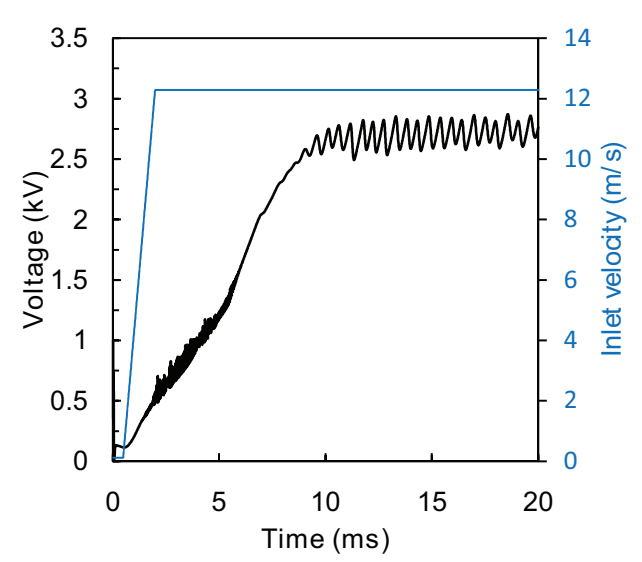

Fig. 10. Simulated arc voltage versus time. $\mathrm{I}=400 \mathrm{~mA} . \mathrm{Q}_{\text {air }}=0.32 \mathrm{~g} / \mathrm{s}$.

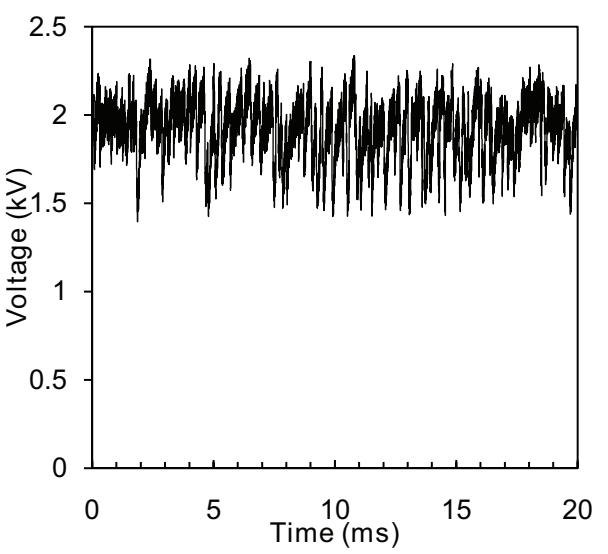

Fig. 11. Typical experimental voltage oscillogram. $Q_{a i r}=0.32 \mathrm{~g} / \mathrm{s} . \mathrm{I}=400$ $\mathrm{mA}$.

Thus, the LTE assumption is probably the main reason of this discrepancy, even if some other factors could intervene e.g. the metal vapor near the electrodes.

After the arc has reached the tip, we can also observe numerically, on Fig. 10 the apparition of voltage instabilities. These instabilities arise from a coming and going motion of the arc bend, which change the arc length and thus the voltage drop. Instabilities are also observed experimentally and can be seen on Fig. 11. The normalized FFT of both experimental and simulated voltage oscillograms (for $\mathrm{t}>10$ ms) are presented on Fig. 12, in a semilogarithmic scale. The experimental spectrum is broad, whereas the simulated is thinner but shows several frequency peaks. The oscillation frequency peaks are in the same range of frequencies. The highest peak is for a frequency of $1.85 \mathrm{kHz}$ and $3.2 \mathrm{kHz}$ for the numerical and experimental spectrum, respectively. Let us point out that the $43 \mathrm{kHz}$ peak directly comes from the power supply frequency which is based on a resonance converter. Hence the instabilities over $10 \mathrm{~ms}$ could be due mainly to hydrodynamic forces. Even if the arc root stays at a fixed position (similar to the steady mode) these periodic fluctuations, coming from the arc plume length, remind the takeover mode [44].

The Joule heating $(\boldsymbol{J} \cdot \boldsymbol{E})$ balances the radiation losses and the convective cooling effect driven by the Lorentz forces 


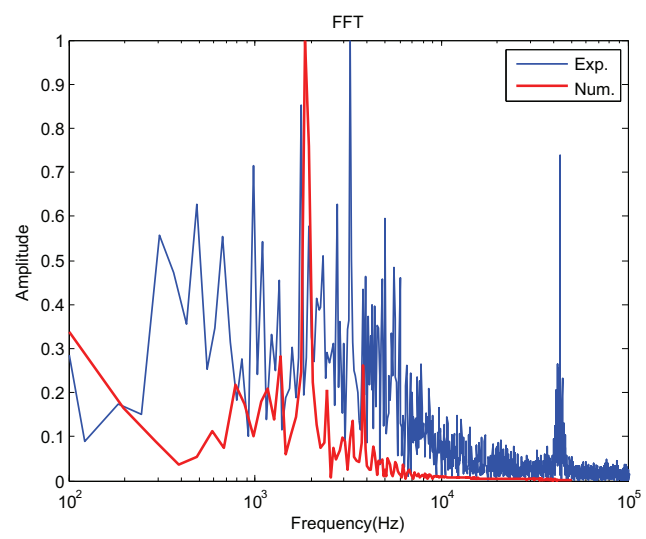

Fig. 12. Comparison between the normalized FFT of the experimental and the numerical voltage oscillograms, plotted in a semilogarithmic scale. I = $400 \mathrm{~mA}$. Q $\mathrm{air}=0.32 \mathrm{~g} / \mathrm{s}$.

[18], almost negligible in our case. In low current plasma torches, the convective cooling effect mostly comes from the gas inflow. The Joule heating is strong $\left(27 \mathrm{~kW} / \mathrm{cm}^{3}\right)$ in the anodic zone, where the current density is maximum, but lower than $1 \mathrm{~kW} / \mathrm{cm}^{3}$ in the rest of the arc due to the low current used.

\section{B. Influence of the current}

The current influence has been investigated in the range of $300 \mathrm{~mA}-600 \mathrm{~mA}$ for an air flow rate of $0.32 \mathrm{~g} / \mathrm{s}$.

Fig. 13 shows photographs of the plasma plume vs. electrical current. The higher the current, the higher the power and the stability. Indeed, for $\mathrm{I}=300,400$ and $600 \mathrm{~mA}$, the experimental deposited power is 640,770 and $950 \mathrm{~W}$ respectively.

Fig. 14 shows the numerical oscillograms for $\mathrm{I}=300$, 400 and $600 \mathrm{~mA}$ and on Figs. 11 and 15 the associated experimental oscillograms. On Fig. 14, we can observe that, before the arc root reached the cathode tip $(\mathrm{t}<10 \mathrm{~ms})$, the higher the current, the lower the instabilities magnitude.

The mean voltage drop, showed on Fig. 16, and the standard deviation for the three cases, both experimental and simulated, have been reported on Table II. The model follows the experimental voltage trends: the higher the current, the lower the voltage but the higher the deposited power. This is a typical characteristic of non-thermal plasmas. For $\mathrm{I}=300,400$ and $600 \mathrm{~mA}$, the numerical deposited power is 1000, 1100 and $1200 \mathrm{~W}$ respectively.

Moreover, one can observe that the higher the current, the higher the instabilities magnitude. The oscillation frequencies are in the same frequency range for the three currents.

We can also notice that the lower the current, the higher the difference between simulated and experimental mean voltage. This phenomenon is probably due to the non-equilibrium effects which increase when decreasing the current.

The radial profile of the temperature in the middle of the cathode is shown on Fig. 17. The higher the current, the higher the temperature and the wider the arc core temperature profile. As a result, the higher the temperature, the higher the arc root
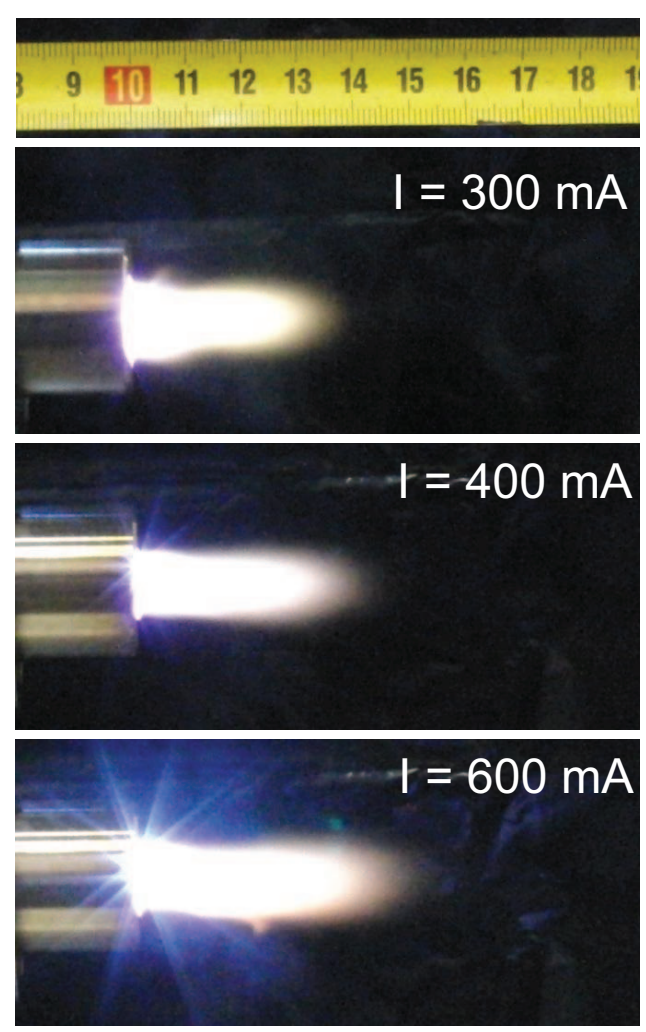

Fig. 13. Photographs of the experimental plasma for three currents. $\mathrm{Q}_{\text {air }}=$ $0.32 \mathrm{~g} / \mathrm{s}$.

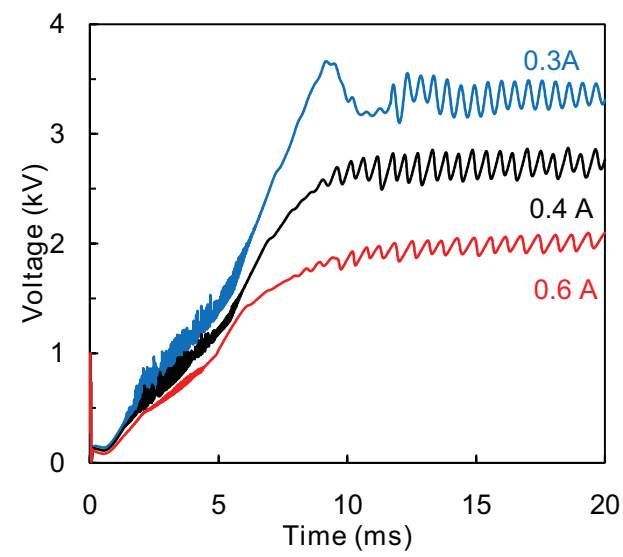

Fig. 14. Numerical arc voltage vs. time for three different currents. Qair $=$ $0.32 \mathrm{~g} / \mathrm{s}$.

TABLE II

COMPARISON BETWEEN EXPERIMENTAL AND NUMERICAL RESULTS OF THE MEAN VOLTAGE AND STANDARD DEVIATION IN FUNCTION OF THE CURRENT. $\mathrm{Q}_{\text {air }}=0.32 \mathrm{G} / \mathrm{S}$.

\begin{tabular}{cccc}
\hline I $(\mathrm{A})$ & & Mean voltage $(\mathrm{kV})$ & Standard deviation $(\mathrm{kV})$ \\
\hline 0.3 & Exp. & 2.13 & 0.61 \\
& Num. & 3.31 & 0.10 \\
\hline 0.4 & Exp. & 1.92 & 0.17 \\
& Num. & 2.70 & 0.09 \\
\hline 0.6 & Exp. & 1.58 & 0.14 \\
& Num. & 2.00 & 0.05 \\
\hline
\end{tabular}

velocity: $14.3,15.2$ and $16 \mathrm{~m} / \mathrm{s}$ for $\mathrm{I}=300,400$ and $600 \mathrm{~mA}$, respectively. 


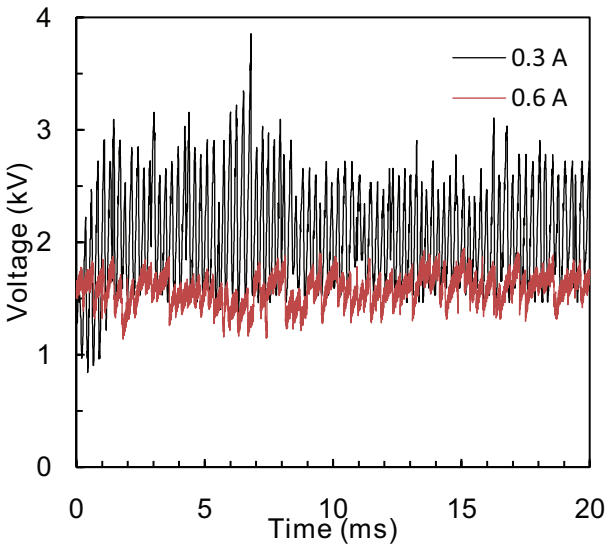

Fig. 15. Experimental oscillograms for $\mathrm{I}=300$ and $600 \mathrm{~mA}$. Q $\mathrm{Q}_{\text {air }}=0.32$ $\mathrm{g} / \mathrm{s}$

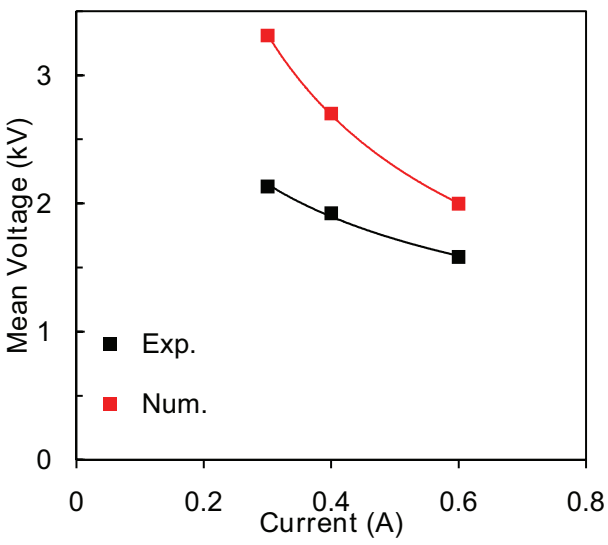

Fig. 16. Comparison of mean voltage drop between experimental and numerical results vs. current. $\mathrm{Q}_{a i r}=0.32 \mathrm{~g} / \mathrm{s}$.

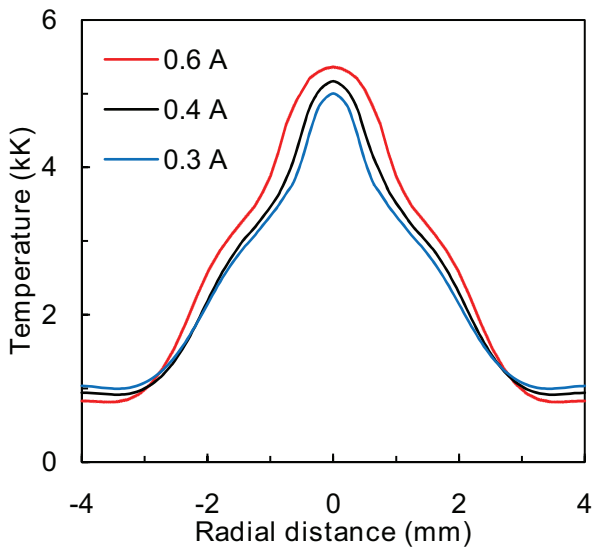

Fig. 17. Radial temperature profile at $\mathrm{z}=35 \mathrm{~mm}$ (middle of the cathode) for three different currents. Qair $=0.32 \mathrm{~g} / \mathrm{s}$.

\section{Influence of the air mass flow rate}

The influence of the air flow rate has been investigated in the range of $0.16-0.5 \mathrm{~g} / \mathrm{s}$ for a current of $400 \mathrm{~mA}$.

Fig. 18 shows that the increase of the air flow rate results in the increase of voltage instabilities. For an air flow rate of $0.5 \mathrm{~g} / \mathrm{s}$, the arc shape is very disturbed by the flow instabilities appearing in the post-discharge zone. An example is shown on

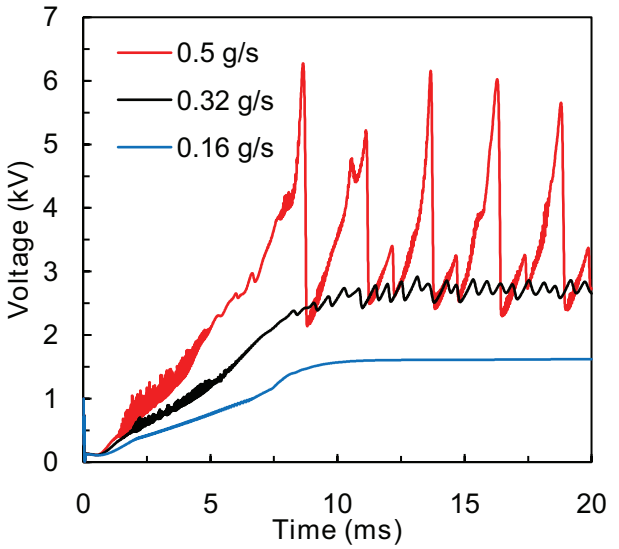

Fig. 18. Numerical arc voltage versus time for three different air flow rates. $\mathrm{I}=400 \mathrm{~mA}$.

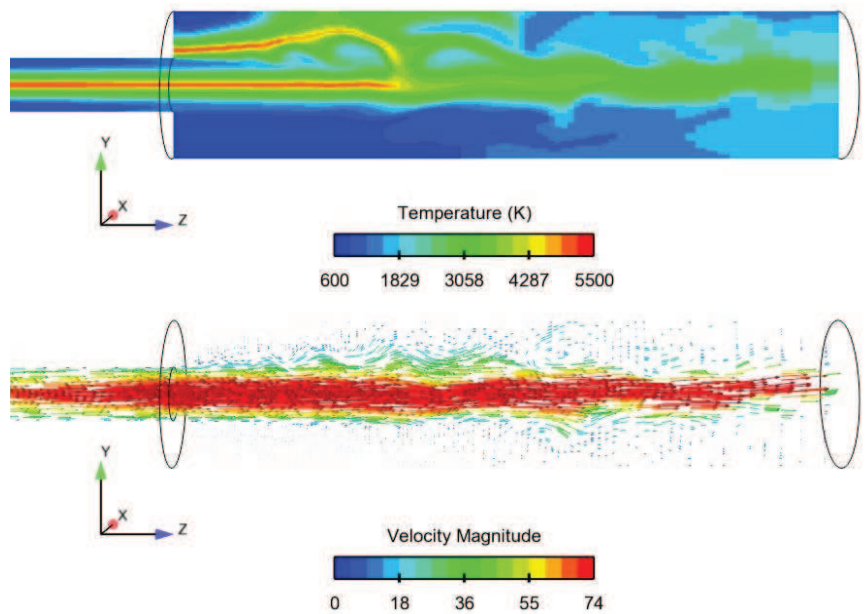

Fig. 19. Temperature distribution and velocity vectors field illustrating the instabilities. Q Q air $=0.5 \mathrm{~g} / \mathrm{s}$. I $=400 \mathrm{~mA} . \mathrm{t}=20 \mathrm{~ms}$.

Fig. 19. The simulated oscillations of the jet implies a periodic and significant arc voltage increase in order to maintain the arc. The voltage shapes remind the three operation modes [44]: steady, takeover and restrike for $0.16,0.32$ and $0.5 \mathrm{~g} / \mathrm{s}$ respectively. Even if those are simulated results, two candidate mechanisms for such instabilities should need further studies to confirm or not their role in this case: the instability of a jet in a cavity, and the Kelvin-Helmholtz instability.

The first process involves the instability of the pressure field surrounding the jet near the inlet. This is a classical version of the Coanda instability, and has been reported even in the case of thermal jets [45]. In our case, it results in an oscillation of the jet, but observational evidence reports that in similar cases, wall-hugging jets can be also observed.

Table III shows that, as observed experimentally, the higher the air flow rate, the higher the voltage drop and the higher the instabilities. We can also observe that the higher the mass flow rate, the higher the discrepancy between simulated and numerical mean voltage. Indeed, the higher the mass flow rate, the higher the cooling of the arc by convection heat transfer, and the higher the non-equilibrium effects.

The radial profiles of the temperature and velocity in the 
TABLE III

COMPARISON BETWEEN EXPERIMENTAL AND NUMERICAL RESULTS OF THE MEAN VOLTAGE AND STANDARD DEVIATION IN FUNCTION OF THE AIR FLOW RATE. I $=400$ MA.

\begin{tabular}{cccc}
\hline$Q_{\text {air }}(\mathrm{g} / \mathrm{s})$ & & Mean voltage $(\mathrm{kV})$ & Standard deviation $(\mathrm{kV})$ \\
\hline 0.16 & Exp. & 1.73 & 0.17 \\
& Num. & 1.61 & 0.01 \\
\hline 0.32 & Exp. & 1.92 & 0.17 \\
& Num. & 2.70 & 0.09 \\
\hline 0.5 & Exp. & 1.94 & 0.21 \\
& Num. & 3.49 & 0.92 \\
\hline
\end{tabular}

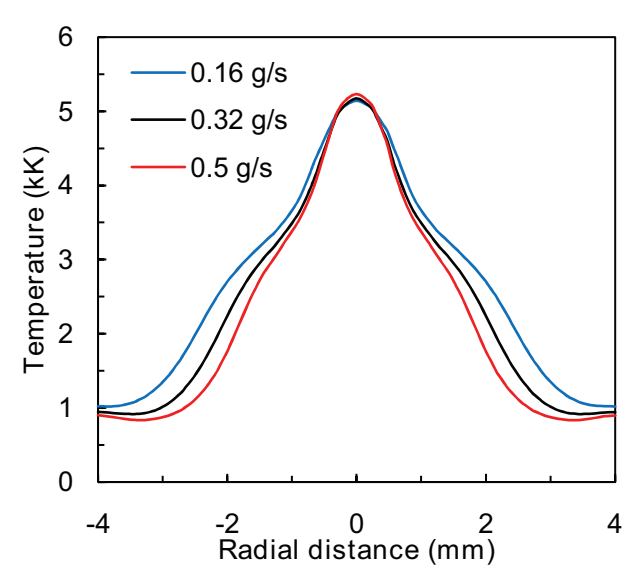

Fig. 20. Numerical radial temperature profile at $\mathrm{z}=35 \mathrm{~mm}$ for different air flow rates. $\mathrm{I}=400 \mathrm{~mA}$.

middle of the cathode are shown on Figs. 20 - 21 respectively. The lower the mass flow rate, the wider the temperature profile. We can notice that the maximum temperature reached in the center of the arc core for the three mass flow rates are very close (between 5140 and $5230 \mathrm{~K}$ ). Hence, the arc core temperature depends mainly of the current and the mass flow tends to cool down the arc core outline. The maximum velocity is equal to $30 \mathrm{~m} / \mathrm{s}$ for $\mathrm{Q}_{\text {air }}=0.16 \mathrm{~g} / \mathrm{s}$ and $62 \mathrm{~m} / \mathrm{s}$ for $\mathrm{Q}_{\text {air }}=0.5 \mathrm{~g} / \mathrm{s}$.

At low flow rates, the velocity profile is relevant of the pure laminar parabolic case. It can also been seen that at higher air flow rates, deviations to this reference profile are retrieved, even if no turbulence model is activated in the code. At the corresponding regimes $(\mathrm{Re}=2000$, typically) transitional mechanisms toward turbulence are strictly impossible to inhibit, so this distortion of the velocity profile can be linked with several candidate processes, from purely numerical effects to physical mechanisms, such as the Kelvin-Helmholtz instability that generally develops in the shear-stress zone surrounding jets. In our case, the vortex creation that should progressively occurs at scales between the grid size and the jet diameter, resulting in an increase of the mean velocity in this mixing layer is not observable, but there remains the evidence of a macro-scale shear-stress effect. This has already been described by Trelles et al. [21].

\section{CONCLUSION}

The MHD unsteady modeling of a non-thermal DC nontransferred low current - high voltage plasma torch operating with air has been successfully implemented. The low current

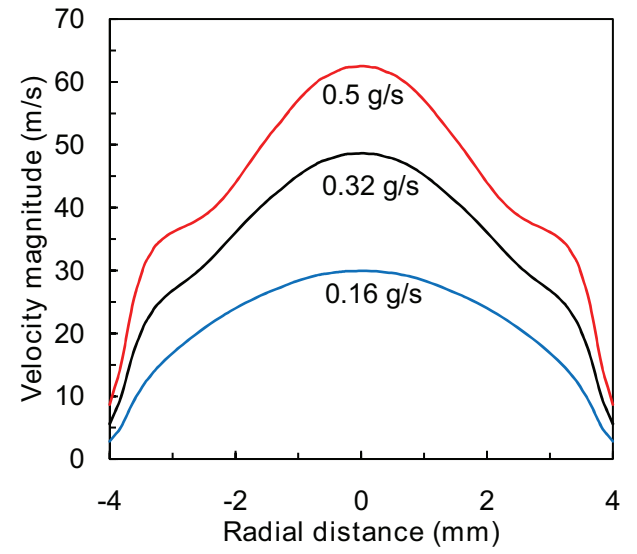

Fig. 21. Numerical radial velocity profile at $\mathrm{z}=35 \mathrm{~mm}$ for different air flow rates. $\mathrm{I}=400 \mathrm{~mA}$.

arc discharges are characterized by a highly irregular and unstable motion of the arc column which is particularly difficult to simulate due to numerical instabilities. Significant information, experimentally hardly accessible, have been obtained.

Among the most important results to point out, one can quote:

- The numerical arc moves linearly along the same plane and has the same shape as the experimental one. Due to a velocity dead zone at the cathode tip, the arc root is attached few mm above the cathode tip as observed experimentally.

- The magnetic field and the Lorentz force are very low because of the low current applied to the anode. The arc column is very stable in the nozzle because of the wall-stabilization of the arc. At the nozzle tip, the low current leads to instabilities in the arc length and thus in the voltage which could be linked to pure hydrodynamic effects.

- The model overestimates the voltage drop probably because of the LTE assumption. Indeed, the non-equilibrium effects are significant and result in a discrepancy between experimental and numerical voltage values.

- The temperature gradients are significant and lead to a highly non-homogeneous arc discharge.

- The arc root radiation is underestimated because the electrode metal evaporation is not taken into account.

- The arc core radius can be estimated between 0.5 and $0.83 \mathrm{~mm}$ by the model.

- For $\mathrm{t}>10 \mathrm{~ms}$, the numerical oscillation frequency range, similar to the experimental one, could probably be due to the hydrodynamic forces.

- The higher the current, the lower the voltage, the higher the deposited power, the higher the arc core temperature and radius, the lower the voltage instabilities.

- The higher the current, the lower the voltage discrepancy between the experimental and numerical results. The higher the air flow rate, the higher the voltage difference between experimental and numerical results. These two phenomenon are probably due to the non-equilibrium 
effects which decrease with increasing the current and decreasing the mass flow rate.

- The higher the air flow rate, the higher the voltage instabilities. Maximum temperatures are similar but the temperature and velocity profiles become narrower.

- For $\mathrm{Q}_{\text {air }} \geq 0.5 \mathrm{~g} / \mathrm{s}$, the jet appears progressively as instable and broadens. Such behavior for the model indicate that experimental confirmation for possible candidate mechanisms may be searched for : Coanda instability and Kelvin-Helmoltz instability.

In a further work, the development of a NLTE model will be considered to take into the high non-equilibrium effects of the plasma torch. The perspective of this preliminary model are also the implementation of a enthalpy flux and a sheath zone at the electrodes and a better description of the inlet zone. The full anode and inlet zone with tangential entry will be meshed in order to take into account the real vortex flow. The laminar flow regime is a strong assumption in our case and turbulent models will be tested to observe their influence on the arc shape and the voltage drop.

The restrike mode will also be implemented to simulate the glidarc behavior, happening for certain values of current and air flow rate. A hot gas column reattachment process, based on the overcome of a fixed value of the electric field, is considered.

This preliminary work is likely to open the way towards a better understanding of low current arc discharges which technologies are currently encountering an important development in many application fields.

\section{ACKNOWLEDGMENT}

The authors gratefully acknowledge the Code_Saturne development team for their technical support.

\section{REFERENCES}

[1] A. Gleizes, J. Gonzalez, and P. Freton, "Thermal plasma modelling," J. Phys. D, Appl. Phys., vol. 38, no. 9, pp. R153-R183, May 2005.

[2] J. P. Trelles, C. Chazelas, A. Vardelle, and J. V. R. Heberlein, "Arc Plasma Torch Modeling," J. Therm. Spray Tech., vol. 18, no. 5-6, pp. 728-752, Dec. 2009.

[3] L. Chemartin, P. Lalande, E. Montreuil, C. Delalondre, B. G. Cheron, and F. Lago, "Three dimensional simulation of a DC free burning arc. Application to lightning physics," Atmospheric Research, vol. 91, no. 2-4, Sp. Iss. SI, pp. 371-380, Feb. 2009.

[4] J. Gonzalez, F. Lago, P. Freton, M. Masquere, and X. Franceries, "Numerical modelling of an electric arc and its interaction with the anode: part II. The three-dimensional model-influence of external forces on the arc column," J. Phys. D, Appl. Phys., vol. 38, no. 2, pp. 306-318, Jan. 2005.

[5] S. W. Chau, K. L. Hsu, D. L. Lin, J. S. Chen, and C. C. Tzeng, "Modeling and experimental validation of a 1.2 MW DC transferred well-type plasma torch," Computer Physics Communications, vol. 177, no. 1-2, pp. 114-117, Jul. 2007.

[6] A. Blais, P. Proulx, and M. Boulos, "Three-dimensional numerical modelling of a magnetically deflected dc transferred arc in argon," $J$. Phys. D, Appl. Phys., vol. 36, no. 5, pp. 488-496, Mar. 2003.

[7] A. Douce, C. Delalondre, H. Biausser, and J. Guillot, "Numerical modelling of an anodic metal bath heated with an argon transferred arc," ISIJ International, vol. 43, no. 8, pp. 1128-1135, 2003.

[8] E. Moreau, C. Chazelas, G. Mariaux, and A. Vardelle, "Modeling the restrike mode operation of a DC plasma spray torch," J. Therm. Spray Tech., vol. 15, no. 4, pp. 524-530, Dec. 2006.
[9] B. Selvan, K. Ramachandran, K. P. Sreekumar, T. K. Thiyagarajan, and P. V. Ananthapadmanabhan, "Three-Dimensional Numerical Modeling of an Ar-N2 Plasma Arc Inside a Non-Transferred Torch," Plasma Sci. Technol., vol. 11, no. 6, pp. 679-687, Dec. 2009.

[10] B. Selvan and K. Ramachandran, "Comparisons Between Two Different Three-Dimensional Arc Plasma Torch Simulations," J. Therm. Spray Tech., vol. 18, no. 5-6, pp. 846-857, Dec. 2009.

[11] B. Selvan, K. Ramachandran, K. P. Sreekumar, T. K. Thiyagarajan, and P. V. Ananthapadmanabhan, "Numerical and experimental studies on DC plasma spray torch," Vacuum, vol. 84, no. 4, pp. 444-452, Dec. 2009.

[12] M. I. Boulos, P. Fauchais, and E. Pfender, Thermal PlasmasFundamentals and Applications vol 1, I. 0306446, Ed. New York Plenum, 1994.

[13] Q. Zhou, H. Li, X. Xu, F. Liu, S. Guo, X. Chang, W. Guo, and P. Xu, "Comparative study of turbulence models on highly constricted plasma cutting arc," J. Phys. D, Appl. Phys., vol. 42, no. 1, p. 015210, Jan. 2009.

[14] A. B. Murphy, "The effects of metal vapour in arc welding," J. Phys. D, Appl. Phys., vol. 43, no. 43, Nov. 2010.

[15] H.-P. Li and E. Pfender, "Three dimensional modeling of the plasma spray process," J. Therm. Spray Tech., vol. 16, no. 2, pp. 245-260, Jun. 2007.

[16] C. Baudry, A. Vardelle, and G. Mariaux, "Numerical modeling of a DC non-transferred plasma torch: Movement of the arc anode attachment and resulting anode erosion," High Temp. Mat. Proc., vol. 9, no. 1, pp. $1-15,2005$.

[17] P. Freton, J.-J. Gonzalez, and G. Escalier, "Prediction of the cathodic arc root behaviour in a hollow cathode thermal plasma torch," J. Phys. D, Appl. Phys., vol. 42, no. 19, p. 195205, Oct. 2009.

[18] K. M. Tang, J. D. Yan, C. Chapman, and M. T. C. Fang, "Threedimensional modelling of a dc arc plasma in a twin-torch system," $J$. Phys. D, Appl. Phys., vol. 43, no. 34, p. 345201, Sep. 2010.

[19] A. Kaddani, S. Zahrai, C. Delalondre, and O. Simonin, "Threedimensional modeling of unsteady high-pressure arcs in argon," J. Phys. D, Appl. Phys., vol. 28, no. 11, pp. 2294-2305, Nov. 1995.

[20] P. Freton, J. Gonzalez, and A. Gleizes, "Comparison between a two- and a three-dimensional arc plasma configuration," J. Phys. D, Appl. Phys., vol. 33, no. 19, pp. 2442-2452, Oct. 2000.

[21] J. P. Trelles, J. V. R. Heberlein, and E. Pfender, "Non-equilibrium modelling of arc plasma torches," J. Phys. D, Appl. Phys., vol. 40, no. 19, pp. 5937-5952, Oct. 2007.

[22] J. Park, J. Heberlein, E. Pfender, G. Candler, and C. H. Chang, "TwoDimensional Numerical Modeling of Direct-Current Electric Arcs in Nonequilibrium," Plasma Chem. Plasma Process., vol. 28, no. 2, pp. 213-231, Apr. 2008.

[23] D. Bernardi, V. Colombo, E. Ghedini, and A. Mentrelli, "Comparison of different techniques for the FLUENT (C) -based treatment of the electromagnetic field in inductively coupled plasma torches," Eur. Phys. J., D, vol. 27, no. 1, pp. 55-72, Nov. 2003.

[24] C. Delalondre, S. Zahrai, and O. Simonin, "Turbulence Modelling in Electric Arc," Internation Symposium on Heat and Transfer under Plasma Conditions, 1994.

[25] J. Bauchire, J. Gonzalez, and A. Gleizes, "Modeling of a DC plasma torch in laminar and turbulent flow," Plasma Chem. Plasma Process., vol. 17, no. 4, pp. 409-432, Dec. 1997.

[26] A. Fridman, A. Chirokov, and A. Gutsol, "Non-thermal atmospheric pressure discharges," Journal of Physics D: Applied Physics, vol. 38, no. 2, p. R1, 2005.

[27] G. Petitpas, J. Gonzalez-Aguilar, A. Darmon, and L. Fulcheri, "Ethanol and E85 Reforming Assisted by a Non-thermal Arc Discharge," Energy Fuels, vol. 24, no. 4, p. 2607, Apr. 2010.

[28] J.-D. Rollier, J. Gonzalez-Aguilar, G. Petitpas, A. Darmon, L. Fulcheri, and R. Metkemeijer, "Experimental Study on Gasoline Reforming Assisted by Nonthermal Arc Discharge," Energy Fuels, vol. 22, no. 1, p. 556, Jan. 2008.

[29] J. Gonzalez-Aguilar, G. Petitpas, A. Lebouvier, J.-D. Rollier, A. Darmon, and L. Fulcheri, "Three Stages Modeling of n-Octane Reforming Assisted by a Nonthermal Arc Discharge," Energy Fuels, 2009.

[30] J.-D. Rollier, G. Petitpas, J. Gonzalez-Aguilar, A. Darmon, L. Fulcheri, and R. Metkemeijer, "Thermodynamics and kinetics analysis of gasoline reforming assisted by arc discharge," Energy Fuels, vol. 22, no. 3, pp. 1888-1893, May 2008.

[31] G. Petitpas, J.-D. Rollier, A. Darmon, J. Gonzalez-Aguilar, R. Metkemeijer, and L. Fulcheri, "A comparative study of non-thermal plasma assisted reforming technologies," International Journal of Hydrogen Energy, vol. 32, no. 14, pp. 2848-2867, Sep. 2007. 
[32] L. Bromberg, "CFD modeling of Plasmatron Methane Reformer," 2005, rapport interne, PSFC/JA-05-14.

[33] A. Chirokov, A. Gutsol, A. Fridman, and L. Kennedy, "Reversevortex plasma stabilization: experiments and numerical simulation," in Proceedings of the 15th International symposium on plasma chemistry, Orleans, 2001.

[34] Y. Tanaka, "Thermally and chemically non-equilibrium modelling of Ar- $\mathrm{N}_{2}-\mathrm{H}_{2}$ inductively coupled plasmas at reduced pressure," Thin Solid Films, vol. 518, no. 3, pp. 936-942, Dec. 2009.

[35] A. D'Angola, G. Colonna, C. Gorse, and M. Capitelli, "Thermodynamic and transport properties in equilibrium air plasmas in a wide pressure and temperature range," Eur. Phys. J. D, vol. 46, no. 1, pp. 129-150, Jan. 2008.

[36] Y. Naghizadeh-Kashani, Y. Cressault, and A. Gleizes, "Net emission coefficient of air thermal plasmas," J. Phys. D, Appl. Phys., vol. 35, no. 22, pp. 2925-2934, Nov. 2002.

[37] F. Archambeau, N. Mechitoua, and M. Sakiz, "Code_Saturne: a finite volume code for the computation of turbulent incompressible flows," International Journal on Finite Volumes, vol. 1, no. 1, Feb. 2004.

[38] J. Van Doormaal and G. Raithby, "Enhancements of the SIMPLE method for predicting incompressible fluid flows," Numer. Heat Transf., vol. 7 , no. 2, pp. 147-163, 1984.

[39] N. Sanders and E. Pfender, "Measurement of anode falls and anode heat-transfer in atmospheric-pressure high-intensity arcs," J. Appl. Phys., vol. 55, no. 3, pp. 714-722, 1984.

[40] J. P. Trelles, E. Pfender, and J. V. R. Heberlein, "Modelling of the arc reattachment process in plasma torches," Journal of Physics D: Applied Physics, vol. 40, no. 18, p. 5635, 2007. [Online]. Available: http://stacks.iop.org/0022-3727/40/i=18/a=019

[41] L. Chemartin, P. Lalande, C. Delalondre, B. Cheron, H. Andreu, and C. Andre, "3D simulation of electric arc column for lightning aeroplane certification," High Temp. Mat. Proc., vol. 12, no. 1-2, pp. 65-78, 2008.

[42] J. M. Park, K. S. Kim, T. H. Hwang, and S. H. Hong, "ThreeDimensional Modeling of Arc Root Rotation by External Magnetic Field in Nontransferred Thermal Plasma Torches," IEEE Trans. Plasma Sci., vol. 32, no. 2, pp. $479-487$, Apr. 2004.

[43] J. Menart and S. Malik, "Net emission coefficients for argon-iron thermal plasmas," J. Phys. D, Appl. Phys., vol. 35, no. 9, pp. 867-874, May 2002.

[44] Z. Duan and J. Heberlein, "Arc instabilities in a plasma spray torch," $J$. Therm. Spray Tech., vol. 11, no. 1, pp. 44-51, Mar. 2002.

[45] M. R. Muller and M. V. Karwe, "The role of inlet location on the dynamics of thin two-dimensional buoyant surface jets," Experiments in Fluids, vol. 2, pp. 137-142, 1984.

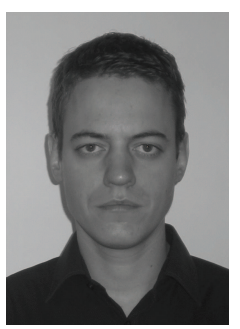

Alexandre Lebouvier was born on December 4, 1985. He received the M.S. degree in plasma processes from the Orleans University, France, in 2008. Since 2008 , he is currently working towards the Ph.D. degree in Energetics at MINES ParisTech, Sophia Antipolis, France

His specialized research areas include experimental and theoretical study of reforming processes for syngas production.

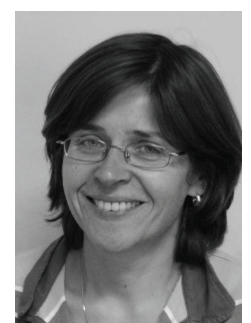

Clarisse Delalondre obtained a Ph.D. degree from Rouen University on electric arc numerical simulation including non-equilibrium sheath modeling. Since 1990, she works at EDF R\&D in a fluids mechanics department (MFEE). She is specialized on numerical simulation of electric arc for industrial applications as welding, arc furnace, plasma torch, circuit breakers, transformer station and lightning. Her research works focus on non-equilibrium phenomena, turbulence and unsteady phenomena, and developments on electric arc simulations has been

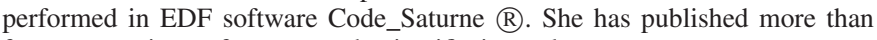
forty papers in conferences and scientific journals.

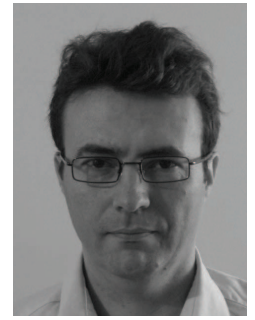

Francois Fresnet was born on March 6, 1972. He received in 2001 a $\mathrm{Ph} . \mathrm{D}$. degree in plasma physics from the University of Paris-Sud XI (Orsay, France). Since 2002, he has been with Renault SAS, France, where he is currently project leader in the framework of Diesel after-treatment systems.

Valerie Boch was born in 1963. She received the Master dedree in aerodynamics from University of Poitiers, France. Since 1987, she has been with Renault SAS, France, where she is currently head of advanced fuel team in the R\&D department.

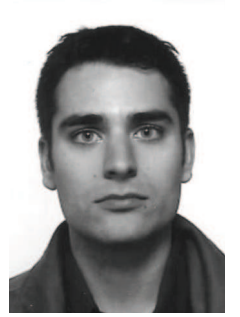

Vandad Rohani was born in Paris, France, in 1980. He received the Ph.D. degree in plasma physics from University of Paris-Sud XI, France, before joining, in 2008, the Center for Energy and Processes of MINES ParisTech, France, as a researcher in plasma physics and part-time lecturer. His research activities are focused on the development of thermal and nonthermal plasma sources for energy applications and chemistry.

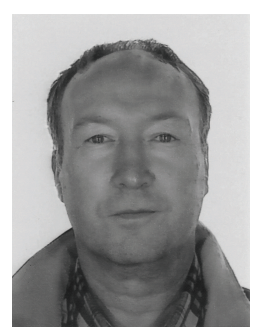

Francois Cauneau obtained a DEA in Astrophysics in 1985 at Observatoire de Paris, and a Ph.D. in 1988 in Remote Sensing at University Paris 7. He is Maitre de Recherches at Ecole des Mines de Paris - Mines ParisTech, where he teaches in fluid dynamics, wind turbines aerodynamics and engines technology.

As a Senior Scientist in the Center for Energy and Process in the same school, he has developed since 1992 several advanced methods in the domain of radar remote sensing for Geophysical flows studies in Meteorology and Oceanography. He is specialised in visualisation techniques and modelling of geophysical and industrial flows, with a special emphasis on decision support systems regarding risk and environmental problems, and has published more than 40 papers in scientific journals and conferences. He has leaded task forces in several international projects for UNEP, IMO and EU, and has participated to the design of the first Numerical Information Systems integrating spatial oceanographic observations for environmental plans. He is working today on adapting the numerical modelling tools of Fluid Mechanics for project management integrating Renewable Energies. 
IEEE TRANSACTIONS ON PLASMA SCIENCE, VOL. 39, NO. 9, SEPTEMBER 2011 @ 2011 IEEE

Digital Object Identifier 10.1109/TPS.2011.2160208

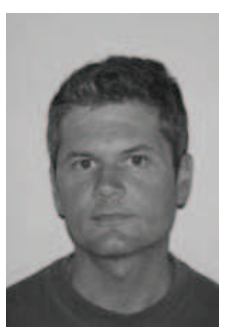

Laurent Fulcheri was born in France in 1960.

Graduated from Ecole Nationale Superieure d'Arts et Metiers (ENSAM-Paris) in 1983, he got a DEA from INP-Grenoble in 1984, a Ph.D. and Habilitation degree in 1989 and 2003, respectively.

He joined Mines-ParisTech (formally Ecole des Mines de Paris) in 1989 as a Senior Researcher, became head of the Plasma Group in 2003 and Maitre de Recherche in 2007. His field of research covers the development of thermal and non-thermal plasma processes for energy and environmental issues. These researches are currently focussing on fossil and renewable hydrocarbon conversion including : reforming, gasification, Gas To Liquid conversion, gas treatment ( $\mathrm{NOx}, \mathrm{COV}$, particles...) and nanostructures synthesis (carbon black, fullerenes, nanotubes).

Laurent Fulcheri has more than thirty papers published in peer review journals, and around ten patents. He participated in many international conferences as invited speaker. 